\title{
Experiences of Families Engaged in Home-Schooling in Accra, Ghana
}

\author{
Nana Esi Badu Nketsiah \\ Department of Psychology and Education \\ University of Education, Winneba \\ Ghana \\ Kwame Winston Abroampa PhD \\ Kwame Nkrumah University \\ Science and Technology, Kumasi \\ Ghana \\ Rev. Kwesi Nkum Wilson PhD \\ Komenda College of Education, Komenda \\ Ghana
}

\begin{abstract}
The study explored the experiences of families engaged in home-schooling in Accra. The research adopted a multi-case study design to explore the experiences of a select group of parents who home-school their children, highlighting their motivation for home-schooling as an alternative to traditional school education. The snowball sampling technique was used to identify three families with children between the ages of 3 to 14 years. Primarily, data were gathered using interviews and observation sessions Data accumulated for the study was analysed by first transcribing interviews recorded. The transcribed interviews were then classified under three major themes which are reasons for homeschooling, curriculum choices and challenges of home-schooling. The study identified several motivations for homeschooling and amongst these, the most prevalent were; a concern about the school environment, a desire to provide a strong moral foundation, dissatisfaction with academic instruction provided in traditional schools and the provision of religious instruction to home-school children. Families also chose from a variety of curricula and resources. However, they found paucity of resource materials, stereotyping of home-schooling and absence of policies as challenges. The study concluded that the motivations for parents choosing home-schooling are consistent across cultures though no previous research has been found to support this in the Ghanaian context. It was recommended that the legal framework and guidelines for home-schooling in Ghana be clearly spelt out by the government of Ghana to permit more and more parents see this option as a viable school choice option.
\end{abstract}

\section{Background to the Study}

The world over, parents generally aspire to engage their children in an educational process of the highest quality structured to holistically develop their wards. Traditionally, the public and private educational institutions have served as the main avenues for achieving such an education and it is only fairly recent, especially in Africa, that other alternative schooling options such as home-schooling has begun to gain recognition as a third option to obtaining an education with the added advantage of simultaneously catering for the idiosyncratic needs of a child. For this reason, in advanced jurisdictions like in the USA, Britain and Canada, it has become more common, socially accepted and legitimised over the years.Home-schooling is the situation where parents or guardians make a conscious decision to provide education for their child or children in place of that provided by schools, and where the parents are the main teachers or facilitators in the programme (Yin, Zakaria \& Baharun, 2016). Such educational programmes range from loose to moderately structured curricula. Nevertheless, it is not a replication of school in a home environment, but a holistic lifestyle that strips off the trappings and restrictions of institutional schooling (Plank, 2004). Since homeschooling is a form of private education that is parent led and home based, it does not rely on either state-run public schooling or institutional private schooling for a child's education (Ray, 2013).

In some countries such as the United States and Canada, the scope of private schools has been broadened to include home-schooling. In these countries the rule that govern home-schooling vary from state to state and province to province (Arai, 2000) but ultimately, these rules take home-schooling into account. While home-schooling within the western context often allows a parent the freedom to educate one's child however they choose, some states have specific laws outlining home-schooling regulations and guidelines (Davidson Institute for Talent Development, 2015). 
According to the California Home-school Network, California, like all other states in America, has a law compelling children to attend public school. However, this law permits two legal exceptions which are attendance at a private school and instruction by a tutor. In this regard, home-schooling families can establish a private school by replication what large private schools do: filing an affidavit with the State, keeping attendance records, offering instruction in the required branches of study and so forth (Orsi, 1999). Some other states have written specific laws to make provision for home-schooling families, however this does not seem to be the case in Ghana.

In Ghana, the 2008 Education Act (Act 778) makes provision for free and compulsory basic education as well as private participation in the provision of education at all levels (The Ghana National Education Campaign Coalition and The Global Initiative for Economic, Social and Cultural Rights, 2014) . The Education Act 2008, Act 778, Section 23 stipulates that "a person or an institution may establish, manage or operate an educational institution in accordance with the guidelines issued, and regulations made on behalf of the Minister of Education in consultation with the Education Service Council and/or the National Accreditation Board''. The United Nations General Assembly at the Millennium Development Summit held in September 2010, mooted for a new global development framework-the Sustainable Development Goal-to replace the MDG. Being one of the 50 countries in which the post-2015 agenda consultations were held from 2012-2013, Ghana was directly involved in the development of the SDG's and as such the goals reflect the aspirations and needs of the people of Ghana. As per Goal 4 of the SDG's, Ghana must ensure inclusive and equitable quality education and promote lifelong learning opportunities for all. Surely, a country that advocates an allinclusive educational policy should be willing to make provision for any deviations to the traditional systems already firmly established. This cannot be achieved without spelling out the legal status of home-schooling in Ghana.

With an increasingly growing population in most parts of the world including Ghana, state-owned institutions could no longer accommodate the volume of learners seeking to be enrolled in school and thus the advent of private institutions set up by individuals or organizations to supplement the inadequate state-owned educational facilities. With the introduction of formal education and free compulsory basic education for children in Ghana, along with the imposition of sanctions for parents who refuse to abide by this law, informal education has slowly taken a backstage to formal education. Whereas home-schooling in the past was the only option for people who did not have access to education either because they could not afford it or were regarded as inferior groups of people, which included girls and other minorities, today many families resort to home-schooling out of their own volition.

The modern home-schooling movement is relatively young, having started only in the late 1960's (Gaiter, 2008) in the western world. This movement is said to have been inspired by an educational theorist called John Holt who in the 1970's, inspired the first cadre of home-schoolers through arguments he raised about educational reform. He argued that, learning in the classroom setting was only geared towards making children complete employees and this served as a form of oppression. Another theorist Raymond Moore underscored this by intimating that early schooling was detrimental to the proper growth of a child. He went further to advocate that children should be given a solid foundation before they were sent off to school. He estimated that age eight was an appropriate age to start school. Over the years, this movement has becoming more popular in developing countries, for which Ghana is no exception. There is overwhelming evidence that homeschooling has made notable gains in absolute numbers in nations as diverse as Australia, Brazil, Canada, England, Japan, Mexico, South Africa, South Korea, Scotland, and Russia (Rothermel, 2015).

The phenomenon of home-schooling though popular in the West is gradually gaining currency in Africa and Ghana in particular. It seems some families in Ghana have adopted home-schooling. The idea of providing alternatives to systems that seem to be cast in stone in many societies has never been a popular one. More so in the field of education, which is largely regarded as a veritable building block and the very fibre of every successful economy, the everincreasing pace of development comes the need for more and better opportunities to education. Aseeming problem arises when examining home-schooling in Ghana because there exists no clearcut government policy on the system and it is unclear if home-education meets the requirement or stands as a viable educational system that satisfies the policy of compulsory basic education. A review of literature does not reveal research that explores the experiences of homeschool families in Ghana and how parents continue to be motivated to opt for this system despite the challenges it may pose for them and their children in the present and future relative to government policy: it appears such an attempt comes into a clear confrontation with the law in Ghana.

Evidence from Education Sector Performance Reports over the years show that enrolment into basic schools have increased, indirectly suggesting the number of out-of school children has drastically dropped over the past few years with the introduction of the Free Compulsory Basic Education Programme and other interventions like the free school uniform and free school feeding programmes. 
Though, this is an indication that more children have been enrolled in basic schools, the reports do not take into account children who are being schooled at home, however insignificant this number may be. This implies that they is not much official information publicly available about home-schooling in Ghana. More over its status with regard to educational policy is unclear since no provision is made for it in any of the educational reforms or policies in Ghana. The study thus sought to fill this lacuna by exploring the experiences and motive of parents who are home-schooling their wards in Ghana. Specifically, the study answered the following research questions;

1. What factors influenced the decision of families to home-school their children?

2. What array of curricula and pedagogy choices do home-schooled children experience?

3. What challenges are experienced by families using home-schooling programmes?

\section{Curricula for Home-schooling}

Choosing appropriate, quality curricula is an important part of any educational system (Pannone, 2014). Perhaps one of the first things many parents are likely to consider after taking the decision to home-school is the type of curricula to use. Part of the appeal of home-schooling is the opportunity of choosing one's own curriculum, however this can also be a daunting task. The process of selecting the right curriculum can be very tedious and time-consuming, particularly due to the hundreds of curricula available. Research carried out by Patterson, Gibson, Koenigs, Maurer, Ritterhouse, Stockton and Taylor (2007) found that home-school families have more curriculum choices available to them. Given this vast array of curricula choices, home-school families have become more creative with their curriculum choices (Hanna, 2012), sometimes even inculcating elements such as field trips and outdoor experiments. Various authors have postulated different approached and models which may be placed under any of the following;Traditional Homeschooling Model:In a traditional homeschooling model, the parent takes the lead as the teacher. Many homeschooling families begin with this model, especially if their children are in preschool or elementary school. Parents take full responsibility for planning and managing instruction. Parents often supplement instructional resources with purchasable curricula that fit their educational goals.

An Internet-Based Curriculum:In this homeschooling model, students enroll in an online school. Families select selfpaced curricula where students learn at their own pace, or enroll in virtual classrooms where teachers teach via electronic classrooms. This is often a more popular model for older learners, especially for more academic subjects. Some curricula may offer specific units that learners can download or access independently, while others hold students to a routine and have them log in at a specific time and day to interact with other homeschooling learners to encourage discussions and small group work.

Local Homeschooling Co-op: A homeschooling co-op works to harness its individual members' strengths for the benefit of the group. For example, one parent may teach English while another teaches mathematics and a third teaches music. Parents volunteer to contribute and hire for subjects none of them is able to teach. Families find one another through local homeschooling communities. An Internet-Based Co-op: This homeschooling model basically exists as a more modern take on a local homeschooling co-op except that it occurs mostly online. Learners use Skype or other platforms to attend classes taught in real time by a tutor, teacher and/or parent. Some co-ops may create content material around curriculum available online, such as the free courses available in a university. For internet-based coops and internet based curriculum to work, the home school environment requires gadgets and high speed internet connectivity. Delivery modes may be asynchronous or synchronous. A Blended/Eclectic Curriculum: Many home school families find that blending different approaches to homeschooling works best for them. For example, a family may participate in a local homeschooling co-op for core subjects such as math, English, and science but Skype with a native speaker to learn French. Likewise, other families may opt to teach material themselves but purchase specific internet curriculum for other subjects. It thus adopts the buffet approach by picking bits and pieces of curriculum resources that suite their needs and learners' interest.

\section{Methods}

\section{Research Design}

The multiple case study design was adopted for this study. A multiple case study enabled the researcher to explore differences within and between cases (Baxter \& Susan, 2008)by examining the experiences of 3 families in Accra engaged in home-schooling. In describing something as complex as a parent's decision to home-school a child.It was necessary to adopt techniques that opened up the parent's thinking, values, opinions and experiences (Scheriff, 2008). The design thus helped not only to describe the phenomenon but also to analyse the data in such a way that patterns can be observed (Scheriff, 2008). The study area for the research was Accra, Ghana. Accra is the capital and largest city of Ghana. The majority of residents in the city are middle-income families. 
According to a report on privatization of schools in Ghana submitted by the Ghana National Education Campaign Coalition and the Global Initiative for Economic, Social and Cultural Rights, private schools are an urban phenomenon. The Ghana Ministry of Education also states in its 2012/2013 'Report on Basic Statistics and Planning Parameters for Basic Education in Ghana" that, "for all regions there are more public primary schools than private ones except the Greater Accra Region". In this regard, this area was chosen as the setting for the research because it is most probably be the city with the largest population of home-schoolers and this provides an ease to access of participants. For the purposes of this study, the snowball sample technique was employed because of the presumed limited number of families engaged in home-schooling in Accra. Since the country has no clear laws on home-schooling, there is no record of how many home-school families exist in Accra and how they can be located. In this regard, researchers relied on referrals from initial subjects and contacts of friends to generate additional participants for the study. Though, weinitially identified several potential families for the research, 3 families were eventually settled on and used for the study.

In Family A, the family's father is in his early fifties and works as a consultant in an IT firm. He holds a BSc in Business Administration from a university in the United States. He has been married to the mother in the family for a little over 15 years. Though the mother also holds a BSc in Business Administration, she works exclusively as a homemaker and a teacher to their 4 daughters and a son, all of whom have been home-schooled. The two eldest girls have graduated from the home-school environment and are now enrolled in a private school in the vicinity in which they reside. The next two are currently being home-schooled while the youngest is still too young to start. Information about the children are presented in the table below.

Table 1: Gender and Ages of Sample Home-schooled Children - Family A

\begin{tabular}{llll}
\hline Child & Gender & Age & Current Educational Status \\
\hline $\mathbf{1}$ & Female & 14 & $9^{\text {th }}$ Grade \\
$\mathbf{2}$ & Female & 12 & $7^{\text {th }}$ Grade \\
$\mathbf{3}$ & Male & 5 & $1^{\text {st }}$ Grade \\
$\mathbf{4}$ & Female & 3 & Nursery 2 \\
$\mathbf{5}$ & Female & 11 months & Not yet in school \\
\hline
\end{tabular}

In Family B, the family's father works as a senior lecturer in a University in Ghana. He holds a Doctorate degree in Engineering. The mother works part-time as a consultant and holds a Masters degree in water resource management. They have 3 daughters, only the last is being home-schooled. The mother spends the other half of her time teaching their 7 year old daughter at home. The two eldest girls are in a private school and have never been home-schooled. Information about the children is represented in the table below.

Table 2: Gender and Ages of Sample Home-schooled Children - Family B

\begin{tabular}{llll}
\hline Child & Gender & Age & Current Educational Status \\
\hline $\mathbf{1}$ & Female & 14 & $9^{\text {th }}$ Grade \\
$\mathbf{2}$ & Female & 12 & $6^{\text {th }}$ Grade \\
$\mathbf{3}$ & Female & 7 & $2^{\text {nd }}$ Grade \\
\hline
\end{tabular}

In Family C, the family's father is in his seventies and the wife is in her fifties. The father is the CEO of an electrical company while the mother who has a doctorate degree is the founder of an NGO. They have 2 daughters, both of whom were home-schooled till grade one and both of whom have now graduated and enrolled in a private school. Due to their busy schedules, the family engaged a professional teacher to carry out the lessons for their daughters and neither of them ever gave the children any instruction.

Table 3: Gender and Ages of Sample Home-schooled Children - Family C

\begin{tabular}{llll}
\hline Child & Gender & Age & Current Educational Status \\
\hline $\mathbf{1}$ & Female & 14 & $9^{\text {th }}$ Grade \\
$\mathbf{2}$ & Female & 11 & $5^{\text {th }}$ Grade \\
\hline
\end{tabular}

In total, 3 parents, 2 children and one primary instructor took part in the study. Participants were solicited from friends and acquaintances who were in contact with families that were home-schooling their children. The identities of the respondents of the study were protected by using pseudonyms to ensure confidentiality. All the participants of the study were resident in Accra at the time of the study. The instrument used to collect data was an interview guide, observation guide and documentary analysis. This study gathered qualitative data to explore the experiences of 3 selected families engaged in home-schooling in Accra. 


\section{Data Collection Procedure}

Interviews were conducted with each of the families over a period of 2 weeks, with each session lasting for about 2 hours. With each of the interviews, the researchers endeavoured to cover the basic issues with all families and were also able to pursue other questions prompted by responses given. The exact wording and order of the questions changed from family to family in keeping with the exploratory and open-ended nature of the research. (Berg, 1998). All interviews were audio-taped with the consent of the family and the transcriptions of these interviews constituted the main source of data.

Non-participant observation involved observing behaviours of participants and systematically recording the results of the observation. In addition to interviews, an observation guide was developed to enhance the researchers understanding of the dynamics of a home-school setting and the different interactions that go on between the parentteacher and the child-learner. Observation sessions were held with each of the families. This consisted of the moving into the context of the home-school environment of the three families to observe a teaching and learning session. This observation session enhanced the researchers' knowledge about the schooling processes that takes place in the home. Comprehensive notes were taken during the observation session which lasted for about 60 minutes in order to capture the nature of interactions that went on as well as to supplement the interview by taking note of facial expressions and gestures that cannot be captured on tape. Finally, data was collected from existing documents such as syllabuses textbooks, activity books and other essential teaching and learning resources being used at home. They also unearthed interactive techniques and assessment procedures parent-teachers used.

\section{Data Analysis}

Interview data was first transcribed after several playback of recordings of the interviews. The transcripts were then read through several times to determine if there would be a need for any follow-up questions. Audit trail was done to ascertain the reliability of information gathered. Themes were generated from the data and various codes were assigned to them. A summary of the themes and subthemes that guided the analyses and discussions are as follows:

Table 4: Summary of themes

\begin{tabular}{lll}
\hline Themes & Sub-Themes \\
\hline Factors influencing decision $\quad$ to & $\begin{array}{l}\text { Dissatisfaction with curricula and instruction } \\
\text { homeschool }\end{array}$ & Moral decline, character building and religion \\
& Unsafe school environment \\
Curricula choices of homeschoolers & Curricula choices \\
experience & Teaching resources and techniques \\
& Non-accessibility to resources \\
Challenges of homeschool & Societal perception of home-schooling \\
& Absence of policies and regulations on home-schooling \\
\hline
\end{tabular}

Factors that influenced the decision of the parents to home-school their children

A lot is known about the reasons why families decide to home-school in more developed countries where there are policies and structures to support home-schooling families. Educational policy makers in such countries take into account home-schoolers in the formulation of regulations and laws to ensure an all-inclusive education. The limited research available in the African context makes it difficult to identify reasons why some families decide to homeschool in countries where home-schooling seems to be inconsistent with the laws. The U.S. Department of Education's National Center for Education Statistics (2012) proffers eight primary reasons why parents choose to home-school. Out of these 8, the four highest ranked included: a concern about the environment of other schools, a desire to provide moral instruction, a dissatisfaction with academic instruction at the other schools and a desire to provide religious instruction. These reasons were also reflected among the parents selected for this study.

\section{Dissatisfaction with curriculum and instruction}

Most studies on home schooling have indicated parents' dissatisfaction with the kind of instruction and experiences learners are taken through and loss of confidence in the educational system as one of the principal reasons for their choice. This was evident in the responses provided by the families in this current study. 
For instance, parents of family A stated that: "After we moved to Ghana, the kids started school but we weren't satisfied with the outcome. Imagine that our oldest daughter placed 3rd in Twi all 3 terms, out of a roll of 25 pupils and she doesn't even speak Twi. We found that a bit hard to believe..."

The father in family B indicated that: "...Another reason was the fact that her grades (their child) were exceptionally good but we didn't trust this so much. Primarily because most of these international schools like to make up for the exorbitant fees they charge by making it seem like your child is doing very well... we just wanted to know if the grades were legitimate..."

He further explained that: "You see my wife and I are products of the Ghanaian public school system... I guess we just don't trust the quality of education. Public schools are not sufficiently funded to be effective and the private schools are just overrated ... the quality of education provided is not commensurate with the amount of money paid."

The mother in family $\mathrm{C}$ said that: "I work in education and have done a lot of research in the educational sector, especially in Ghana, and I have seen how inadequate some of our educational institutions are."

She again stated that: “...Since one of the crucial stages of a child's development is between the ages of 3 and 5, I wanted to give my children the best chance I could, a solid foundation that they could later build upon in whatever institution they ended up in."

A review of the above reactions suggest that parents opted to home-school their wards because largely, they were dissatisfied with the school system and the way teaching and learning was done. They underrated the educational system and thought it was substandard. Phrases such as "...weren't satisfied with the outcome...", “...we didn't trust this so much..." and "we found it hard to believe", suggested a distrust in the assessment of learners which smacked off the possibility of learners' outcomes not reflecting their true capacities. It could be deduced that these parents have experienced systems in other countries which enabled them appreciate what quality education is and were thus able to compare standards in different contexts to enable them opt for home-schooling.

\section{Religious and Moral concerns}

Religious orientation was also seen as a reason for opting to home-school their children. Their religious background of some of the parents influenced their perception of morality and values that their children should be exposed to. When asked if their religious background had played a role in their decision to home-school the response was that:The father in family A reacted that; “... it would have to be. That was even one of the reason's we moved back to Ghana...As I mentioned, the main reason we moved to Ghana from the States was because of the rapid moral decline we thought was prevalent in the American society. Having relocated, we realised that it wasn't any better here, we soon realised that several elements of the Western culture were gradually seeping into the fabric of Ghanaian society... "The mother in family A also added that: "...my husband and I always felt the need to solidify them, not necessarily in the Christian Faith but more in terms of character building. What is a person's whole character about? It is based on what Christ wants us to be. He says train your child in the way that they should grow. So I believe the parents are supposed to be the first point of training before the children go out..."

In discussing her motivations for home-school, the mother in family $\mathrm{C}$ said that: “...My motivation for home-schooling was primarily religious I think. One of the central figures of my Faith talks about how crucial the initial stages of a child's development is and being in the educational sector myself, I know this to be true... "The foregoing reactions indicate that the families were deeply steeped in their religious beliefs and therefore had expectations regarding morality and value systems the school should expose their children to since it has enormous implications for character building. The use of phrases such as "...moral decline...", it wasn't any better her..." and "...character building..."reflected parents disappointment of and dissatisfaction with the standard of morality in basic schools as a result of which they opted for home-schooling.

\section{Unsafe school environment}

The school is supposed to be a safe place where both teachers and learners are protected from all forms of psychological and physical harm. The environment in which teaching and learning take place must be conducive so as to prop and facilitate the learning of learners with diverse needs. The micro and macro school environment presents stimuli learners interact with to enable them learn. An unsafe learning environment is therefore inimical to learning. Parents thus had strong views about unsafe environment in some schools in Ghana. For instance; The father in family B indicated that: "When we first relocated to Ghana from the US, we put all the kids into private school. Though the first two adapted quickly, the last had some challenges. She was always tired, getting infections regularly and falling sick frequently...we presumed (this) was because of the school environment so we were quite concerned..." 
Another parent said;“... we noticed that she had grown very shy and withdrawn. We began to feel that something wasn't right in the school and that the environment was having a negative effect on her. We thought maybe the home environment would be the best place for her to 're-find herself ..."

A review of the reactions shows that parents were not satisfied with the school environment. Either because of the overcrowded conditionwhich may result in transfer of infectious diseases or interactions with other peers which may influence the behaviour of their children. In comparing the environmenta parent thought the "...home environment would be the best place for her to 're-find herself...".

In the light of the responses provided by the parents in this study, it is evident that parental motivation for homeschooling amongst the 3 sets of families reflects Van Galen's framework for classifying parental motivation. On the one hand, responses provided by parents $\mathrm{A}$ and $\mathrm{B}$ seem to lean towards pedagogical motives because both of these families had their children enrolled in traditional schools before redrawing them on the basis of academic achievement. On the other hand, parent C's motivations reflect an ideological ideal since the mother strongly believed that it was necessary to strengthen the ties between her and her daughters at a very early stage to establish a lasting bond between them. Reasons given for home-schooling are consistent with evidence provided by the National Centre for Educational Statistics (2012) in the United States suggesting that most recurring reasons parents give for home-schooling include: a concern about environment of other schools, a desire to provide moral instruction, a dissatisfaction with academic instruction and a desire to provide religious instruction. These results seem to suggest that parents' motivation for making the choice to take charge of their children's education are consistent across cultures.

\section{Curricula choices and structure of home-schooled children experience}

The traditional "systematized" approach to schooling requires the adoption of specific curricula that guide teaching and learning. The intent of this research question was to explore which curricula is adopted, whether the traditional curriculumor a hybrid curricula re-engineered in order to provide the home-schooler and the child an array of curricula to choose from.

\section{Curricula choices and structure}

In response to the type of curriculum that she uses, a mother in family A stated that: "I mix and match, that's the beauty of it, you get to pick and choose what you want. So I do a combination of both the US and Ghana curricula."

She also said that: "Basically I do a lot of research and read reviews to see which will work best for my children. Since each child is different, I did not use the same curricula for all of them."

Father B on the other hand said that: "We use mostly the American curriculum. With her mom being a curriculum developer, it is relatively easy for her to adapt the curriculum to suit our daughter as well as her environment. She is often able to draw from the British curriculum as well to enrich what our daughter is being taught."

The primary instruction giver for Family $\mathrm{C}$ stated that: "We used the Montessori curriculum and supplemented with some Bahá 'i inspired materials."

With respect to curriculum content and delivery; For family A, the mother indicated that their schedule was very flexible, stating that: "Typically we're supposed to start by 9 and end by 12, that's lunchtime but this is not always the case. I don't believe in having 20 subjects. I just have my Math, English and Bible and anything else we feel like adding."

Contrary to the flexible model adopted by family A, family B's approach is seemed more structured. Thefather of family B stated that: Generally lessons start at 8am to 12pm then there is a 2 hour break for lunch. Then she resumes at $2 \mathrm{pm}$ and has lessons till $4 \mathrm{pm} . .$. For the most part they start on time. My wife is very rigid with it so unless there is an emergency or something out of the ordinary, lessons always start on time.

He added that with respect to the number of subjects: She does a lot, maybe 10. We do the basic Math, English and science but we also do things like Geography.

Similarly, family C indicates that: We have a very structured system so there is no room for laxity. Our daughter has a uniform she wears every day, there is a designated snack time and lunch time and we also have a designated area where lessons are taught." She takes only three subjects that all other subject are related to. These are maths, literacy and natural science...

A gleaning from the foregoing suggests that with regard to curriculum choice and structure, almost all the families adopted an eclectic approach by using a hybrid curriculum which is not overly structured and rigid but also not too flexible and loosely structured. With respect to the type of curriculum, the use of a combination of both the US and Ghana; US and British, the mixture of Montessori and Bahai speaks to the preceding submission. For instance, Ghana's education system or the curriculum for that matter is modelled after the British system. 
The use of the Montessori curriculum laced with Bahai material reflects the desire to develop a 'good child'. This is consistent with parents' choice of home schooling in order to instil moral values and build the character of their children. Typically, a home-school curriculum is not rigid as it is tailored to meet the demands of beneficiaries in the home.

Observation and content analyses of curriculum materials used by the families confirmed that all the families used resources such as Ghanaian reading materials, workbooks and syllabuses and also relied on online foreign materials they have bought or downloaded. The use of the local materials is to prepare the home-school learners to fit seamlessly into the traditional school system later whilst the foreign materials would broaden their horizon. This is consisted with the findings of Avner (1989) and Davis (2011) which suggest that home-school families use a wide array of curricula. Bauman (2001) also opined that parents use several avenues to arrive at a curriculum. His study revealed that $23 \%$ of the home-schoolers that took part in his study used the curriculum from the local public schoolwhile $77 \%$ of those interviewed used materials from a home-school publisher which is in line with the curriculum.

\section{Teaching techniques and resources used}

The various home schooling approached adapted or adopted largely determines the kinds of teaching and learning techniques and strategies used. Due to the eclectic approach employed by the families a mix of various interactive techniques were used. This involved both face to face teaching and instruction and providing enough resources for hands-on experiences thereby making learning activity based. When asked what teaching and learning techniques and resources where used in home- schooling, the mother in family A responded that: May be because of our exposure and experience we've had with different school systems, a bit of materials here and there. We bought and made use of some grade specific books for some subjects like maths, English language etc and also downloaded a lot of relevant workbooks for various subjects. And since usually it's about two or three kids at a time it's easy giving instructions, engaging them, and monitoring activities. So I would say it is activities most of the time...

Similarly, the mother in family B indicated that that they also rely on a lot on materials already in the system: I rely essentially on materials in the system considering the child's level. And it is always a one-on-one kind of interaction since it is only the two of us. Sometimes, especially during reading I provide a lot of support with pronunciation of words. I also make her work alone using workbooks I have downloaded from the net or materials bought online.

Family C focused on developing a 'good child' as a result they relied on some selected Montessori materials such as sensorials, puzzles, blocks and Bahai materials. The family thus indicated that: Since it is all well structured she knows what subject and materials we should be using at a particular point in time... most of what we do is activity based. This gives her a lot of opportunities to do things and discover on her own.

From the observations of teaching and learning across the families, it was evident that the sessions were interactive and cordial. The children were mostly engaged in activities. This may be attributed to the few learners involved and the relationship between the parent or the teacher and the child/children. The more organic and flexible time schedule in the homeschooling milieu puts parents in a position of being connected to, responsible for, and having authority over their children. This is because homeschooling returns a critical social function - the education of children - to the family. The bond created largely influences the interactions that occur. Ray (1990) intimates that due to the increased time together and sharing of experiences between parents and their home-educated children, their social capital increases.

The options for home-school curricula are expansive. This study found that the choice of home-schooling curriculum among the families was heavily shaped by availability and the perceived learning styles of the children. The parents interviewed mainly use textbook-based and literature-based curricula as they are the most accessible. According to Karman (2005) several methods exist for home-schooling and parents choose a method dependent on their philosophy of education and what outcome the families would like to achieve. As a result most home-school families do not rely on one method but draw on elements of several approaches. Some approaches that have gained popularity over the years identified by Taylor-Hough (2010) are the traditional, classical method and eclectic approaches. As families in this study were not aware of all the approaches available to them, it did not appear that what they selected were driven by a particular ideology. However, from the descriptions provided, it can be concluded that they generally adopt the learner-centred approach, in an informal system.

\section{Challenges of home-schooling}

The home-schooling experience may vary across various communities of the world. Circumstances in advanced communities permit home-schoolers to thrive in an accommodating educational environment, the same cannot be said for home-schoolers in Ghana who often have deal with the paucity of learning resources amongst a host of others.Parent A highlighted a number of challenges she faced home-schooling in Ghana by indicating that: "Getting adequate material. 
Maybe when I say adequate it is because of where I am coming from... if we wanted to do a science experiment and I needed a magnifying glass or a magnet, I could just go to a shop and get it. I don't have that luxury here. I have no idea where to find these kinds of things, it's not public knowledge..." "The last I would say is having to battle the stereotype that home-schooled children are anti-social. I feel that that can be true for any child..." "...And if you go through to Legon, then Legon charges you as an international student because the child doesn't have the GES certificate so they consider you an international student..."

On the other hand she suggested that there were a lot of merits of home-schooling, stating that: "We can cover a lot more than he (son) could have covered in school. It takes a lot more time to go through the text books in school and the teachers are often obliged to skip stuff"'Parent B also made mention of a number of challenges by stating that: "I must say it has become a lot easier to home-school in Ghana. Before there wasn't much available, no support system, no one to interact with in the home-schooling circles. But now we have the support group we attend and this has been very helpful."

He added that: "Another thing that we struggled with was when our daughter begun to ask many questions about why she was the only one who didn't 'go to school'. We had to explain to her over and over again before it stuck. "In responding to the question about the merits of home-schooling he stated that: "For the merits, we have also seen a big change in our daughter. She used to be very shy and an introvert but now she is becoming more and more assertive. She is able to talk confidently and of course she doesn't get as sick anymore. 'The mother in family C also stated that:

"The only thing that comes to mind was how people kept being worried that they weren't yet in school. Some friends of mine kept asking if they weren't yet in school and I always responded that they already were." "As for the merit, they are too many to mention. For one I think it gave them a solid foundation and made them very assertive and outgoing, I was very happy with the outcome and if I could do it again, I would."

It may be deduced from the foregoing that, home-schoolers encountered some challenges in Ghana most of which had to do with availability of resources, stereotyping of home-schoolers and the difficulty of getting children to understand why they are not attending school like everyone. Phrases like 'no idea where to find these kinds of things' suggests the difficulty in locating resources needed for teaching and learning. A daughter seeking explanation as to "why she was the only one who didn't 'go to school...'may be frustrating to parents. Besides, it was also noted that the lack of appreciation of the concept and practices of home-schooling led to stereotyping home-schoolers. In spite of these they indicated that advantages of home-schooling are enormous. The challenges cited with home-schooling fell into three main categories. The first related to accessibility to materials, activities and learning environments. All the parents found it very difficult to readily access curriculum and textbooks in the Ghanaian market. They had to rely on their connection to other home-schooling families in western countries as well as expensive online options. Further with this being a rare choice, it was not possible to draw on experience and resources of a well-formed network of homeschoolers, which is a main source of support and activities in countries like the United States and Britain. The attitude of the society towards home-schooling. Many in Ghana are skeptical about this type of educational choice. This places the families in an uncomfortable position of having to constantly defend their reasons for home-schooling. In addition, the popular belief that home-schooled children find it difficult to socialize in the 'real world' which is confirmed by Sherperd (2010), stereotyping of the phenomenon. Finally, the fact that there are no policies or provisions for homeschooling creates a third set of challenges.

Moreau (2012) and Davis (2011) indicate that there is abundance of home-school resources available to homeschoolers. However, accessibility of materials and educational resources was a major challenge for families. This may be as a result of the variation in context. Whereas in the West, there is abundance of resources, the same is not true for Ghana. Parents relied heavily on internet and foreign resources. This may make funding home-schooling very expensive.

\section{Conclusion}

Though there is paucity of literature on home-schooling in Ghana, research suggests that it is a viable school choice. Gradually people are becoming curious about home-schooling and more families may begin to opt for this system as our public school systems continues to fail and good private options price middle class parents out. It thus imperative that more research in this area is carried out to meet the growing curiosity of Ghanaians and to understand policy measured that can be put in place to regulate the phenomenon and to support families that opt for this choice.

Based on the findings and conclusions of the study, it is recommended that: The Ministry of Education in Ghana takes a closer look at educational policies and systems in order to provide more adequate reforms that are all-inclusive.

1. Home-schooling parents should put in place a more formalised means of tracking the progress of their children in the form of cumulative records and transcripts in order to facilitate the smooth transition from home-schooling to traditional schooling. 
The home-school support group be formally registered as a home-school organization in order to be recognized by the state as well as provide adequate support for home-schoolers in Ghana. This may officially draw the attention of policy makers to the growing phenomenon and the need for regulatory and monitoring systems.

\section{References}

Arai, B. A. (2000). Reasons for home schooling in Canada. Canadian Journal on Education, 200-217.

Avner, J. A. (1989). Home schoolers: A forgotten clientele? School Library Journal, 29.

Bauman, K. J. (2001). Home schooling in the United States: trends and characteristics. Washington DC: U.S census bureau population division.

Baxter, P., \& Susan, J. (2008). Qualitative case study Methodology: Study design and implementation for novice researchers. Ontario.

Berg, B. L. (1998). Qualitative research methods for the social sciences (3rd edition). Boston MA: Allyn and Bacon.

Davidson Institute for Talent Development. (2015). Considering homeschooling: A guidebook for investigating an alternative path to education. Retrieved from A Davidson Institute Web site: www.davidsongifted.org

Davis, A. (2011). Evolution of homeschooling. Distance Learning, 29.

Gaiter, M. (2008). Homeschool: An American history. New York: Palgrave MacMillan.

Hanna, L. G. (2012). Homeschooling education: Longitudinal study of methods, materials and curricula. Education and Urban Society, 609-631.

Johnson, C. (2011). No agenda homeschool.

Johnson, W. R. (2014). A multiple case study investigating the influence of homeschool parents' perceptions of success on the learning environment. Lynchburg: Liberty University.

Karman, D. (2005). How to select home school curriculum. Dallas: The Oregon Christian Home Education Association Network.

Moreau, K. (2012). Home schooled vs. public schooled. Michigan.

National Center for Education Statistics (2012). Home-schooling in the states. New York: Department of Education, USA

Orsi, J. (1999). Is Homeschooling Legal? In When your grandchildren homeschool - A guide for interested relatives (pp. 16-17). Carifornia: Califonia Homeschool Network.

Pannone, S. J. (2014, June). Homeschool curriculum choices: A phenomenological study.

Patterson, J. A., Gibson, I., Koenigs, A., Maurer, M., Ritterhouse, G., Stockton, C., \&\& Taylor, M. J. (2007). Resisting bureaucracy: A case study of home schooling. Journal of Thought, 71-86.

Plank, N.D. (2004). Understanding the demand for education. University of Michigan, Unpublished Manuscript

Rothermel, P. (2015). International Perspectives on Home Education: Do We Still Need Schools? The Journal of Educational Alternatives.1, 107-108

Scheriff, J. W. (2008). A descriptive case study of homeschooling and implications for the future of public schools. Unpublished Dissertations, Seton Hall University.

Shepherd, D. (2010). Mommy is my teacher: Qualitative case studies of three families' homeschooling experience. Unpublished Dissertation). Indiana, Ball State, USA.

Taylor-Hough, D. (2010). Are All Homeschooling Methods Created Equal? Unpublished

Manuscript

The Ghana National Education Campaign Coalition and The Global Initiative for Economic, Social and Cultural Rights. (2014). Education privitization in Ghana and its Impact on the realization of the right to education. Accra.

Zakaria, Lee Y.A. R. B. \&Baharun, H. A. (2016). Critical view of home education. Evaluation \& Research in Education.17(2-3):167-178

Ray, B. D. (2013). Homeschooling associated with beneficial learner and societal outcomes but educators do not promote it. Peabody Journal of Education , 88(3),324-341 